\title{
Short Term Outcomes of Laparoscopic versus Open Distal Gastrectomy with D2 Lymph Nodes Dissection for Gastric Cancer: A Prospective Study
}

\author{
S. Abdelaziem ${ }^{1,2 *}$,Tamer A. El-Bakary ${ }^{1,2}$, Hamdy S. Abd Allah ${ }^{1}$ \\ ${ }^{1}$ Department of General Surgery, Tanta University Hospital, Tanta, Egypt \\ ${ }^{2}$ Department of General Surgery, Hamad Medical Corporation (HMC), Doha, Qatar \\ Email: *saziem@hotmail.com
}

How to cite this paper: Abdelaziem, S., El-Bakary, T.A. and Abd Allah, H.S. (2017) Short Term Outcomes of Laparoscopic versus Open Distal Gastrectomy with D2 Lymph Nodes Dissection for Gastric Cancer: A Prospective Study. Surgical Science, 8, 334-347. https://doi.org/10.4236/ss.2017.88037

Received: July 13, 2017

Accepted: August 13, 2017

Published: August 16, 2017

Copyright $\odot 2017$ by authors and Scientific Research Publishing Inc. This work is licensed under the Creative Commons Attribution International License (CC BY 4.0).

http://creativecommons.org/licenses/by/4.0/

cC) (i) Open Access

\begin{abstract}
Background: Laparoscopic distal gastrectomy (LDG) for gastric adenocarcinoma (GA) is gaining more acceptances worldwide. Its results are still controversial. This study aimed to assess short term outcomes of LDG and compare it to the standard open distal gastrectomy. Patients and Methods: 27 patients with GA of the distal $2 / 3$ of the stomach were included and divided into 2 groups; Group A: 15 patients submitted to open distal gastrectomy with D2 lymph node (LN) dissection, and Group B: 12 patients submitted to LDG with D2 LN dissection. Results: The median age was 54 and 54.3 years in group A and $B$ respectively. The median operative time was 118.7 and 210.2 minutes in group A and B respectively. The median safety margin was 6.52 and $5.7 \mathrm{~cm}$ in group $A$ and $B$ respectively while the median number of excised $L N$ was 24.2 and 21.4 in group A and B respectively. One patient in group B had intraoperative bleeding that was controlled laparoscopically. No conversion to open surgery needed in group B. The median number of narcotic doses was 5.9 and 4.25 in group A and B respectively. The median length of hospital stay was 7.2 days in group A and 7.3 days in group B. Three patients in group A and 2 patients in group $B$ had postoperative complications and all were treated successfully conservatively. Conclusion: LDG with D2 LN dissection is oncologically safe with short-term outcomes comparable to those of the open surgery. Gaining more surgeons' experience is necessary to improve these results.
\end{abstract}

\section{Keywords}

Cancer Stomach, Distal Gastrectomy, Laparoscopic Resection 


\section{Introduction}

Gastric adenocarcinoma (GA) is a leading cause of cancer-related deaths all over the world [1]. Surgical resection of the non-metastatic GA is the treatment of choice as it gives the patient acceptable long-term survival rates [2]. According to the Japanese Gastric Cancer Association treatment guidelines, the standard treatment of advanced GA and early GA with clinically negative nodes (cN0) involving the distal two thirds of the stomach is distal gastrectomy with D2 lymph node (LN) dissection [3]. This operation was performed laparoscopically for the first time by Seijo Kitano in 1994 [4]. Since that time, laparoscopic gastrectomy (LG) for early GA has gained increasing popularity in different countries as it doesn't only offer the patient an excellent chance for cure, but also, all the advantages of minimally invasive surgery including less postoperative pain, shorter hospital stay, faster recovery and better quality of life [5] [6] [7]. However, laparoscopic gastrectomy for GA has its own limitations. It is considered by many surgeons a complicated time consuming technique that requires advanced skills [8] [9]. The aim of this study was to report the short-term outcomes of laparoscopic distal gastrectomy (LDG) with D2 LN dissection in comparison to those of the standard open approach in the treatment of GA involving the distal two thirds of the stomach.

\section{Patients and Methods}

\subsection{Study Design}

This study was conducted during the period from May 2013 to August 2016. It included 27 patients presented by GA to General Surgery Department, Tanta University Hospital, Egypt and Hamad General Hospital, Hamad Medical Corporation, Qatar. All the patients were submitted to full history taking and thorough clinical examination. All the patients had upper gastrointestinal endoscopy and the gastric cancer was biopsied. Histopathological examination confirmed the diagnosis of GA in all patients. Computed tomography (CT) scans of the chest, abdomen and pelvis were obtained to assess the local extent and to exclude distant spread of the tumor. When distant spread was suspected on CT scan, positron emission tomography/CT (PET/CT) was performed before proceeding to curative resection. The $\mathrm{cT}$ and $\mathrm{cN}$ stage of the tumor were assessed using endoscopic ultrasonography (EUA) in all patients. Baseline carcinoembryonic antigen (CEA) level was done for all patients.

Patients with early (cT1) and locally advanced (cT2, cT3) GA involving the distal two thirds of the stomach without distant metastasis (cM0) were included in the study. Exclusion criteria included cT4 tumors, cM1 tumors, recurrent tumors, tumors located in the proximal third of the stomach and other types of gastric cancers (lymphoma, carcinoid and gastrointestinal stromal tumors). $\mathrm{Pa}$ tients with previous upper abdominal surgery and those with American Society of Anaesthiologists (ASA) score more than 3, were also excluded.

All the cases were discussed in a multi-disciplinary team meeting and the de- 
cision was surgical resection for all of them. An informed written consent was obtained from every patient and the study design was approved by the research and ethical committees.

Patients fulfilling selection criteria were divided randomly into 2 groups using the closed envelop method:

- Group A: included 15 patients. In this group, surgery started with staging laparoscopy and when intra-abdominal disease spread was excluded, the surgeon proceeded to midline laparotomy with distal gastrectomy and D2 LN dissection.

- Group B: included 12 patients who were submitted to LDG with D2 LN dissection after exclusion of distant intra-abdominal tumor spread.

\subsection{Surgical Technique}

All patients received prophylactic antibiotics in the form of Ceftriaxone $2 \mathrm{gm}$ and Metronidazole $500 \mathrm{mg}$ intravenously on anesthesia induction. In group (B), the patient was placed in Llyod Davies position, the surgeon stood between the patients, legs with the assistant on the left side and the camera holder on the right side. A thirty degree $10-\mathrm{mm}$ telescope was inserted through a $10-\mathrm{mm}$ port placed $1-\mathrm{cm}$ below the umbilicus. Two $12-\mathrm{mm}$ trocars were inserted $5-\mathrm{cm}$ below the right and left costal margin in the anterior axillary line for the surgeon's hands. A 5-mm trocar is then inserted in the left mid-axillary line 2-cm below the costal margin for the assistant. Another $5-\mathrm{mm}$ trocar is inserted $3 \mathrm{~cm}$ below the xiphoid process to the left of the midline for liver retraction.

The procedure started in all the cases by staging laparoscopy to exclude intra-abdominal spread [Figure 1]. Then, the greater omentum was divided along the avascular plane between it and the transverse colon with dissection of the LN along the greater curvature of the stomach (level 4d). The left gastroepiploic vessels were exposed and divided close to the splenic hilum to ensure removal of the $\mathrm{LN}$ related to them (level $4 \mathrm{sb}$ ). The right gastroepiploic vessels were then exposed and divided in a similar way with removal of the infra-pyloric LN (level 6) [Figure 2]. While the gastric antrum is retracted anteriorly, dissection continues in the plane between the pylorus and $1^{\text {st }}$ part of the duodenum anteriorly and the pancreas posteriorly starting from below upwards. The upper margin of the $1^{\text {st }}$ part of the duodenum and pylorus were dissected dividing the supraduodenal vessels. The right gastric artery is divided at its origin from the hepatic artery proper sweeping the suprapyloric LN (level 5) downwards towards the specimen. The lesser omentum was divided close to its hepatic attachment and the stomach retracted downward and to the left exposing the coeliac trunk and its branches. The common hepatic LN (level 8a) were dissected, the left gastric vessels were dissected and divided with removal of the surrounding LN (level 7) [Figure 3] and the LN around the celiac artery (level 9). The lymph nodes along the proximal lesser curvature were dissected off the gastric wall starting from the cardia downwards till the planned level of gastric division. The $1^{\text {st }}$ part of the duodenum was divided using an endo-GIA stapler [Figure 4]. Then, proximal 


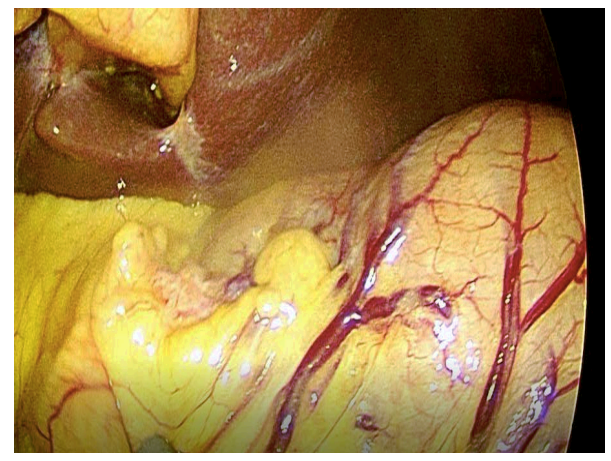

Figure 1. Tumour of the distal third of the stomach.

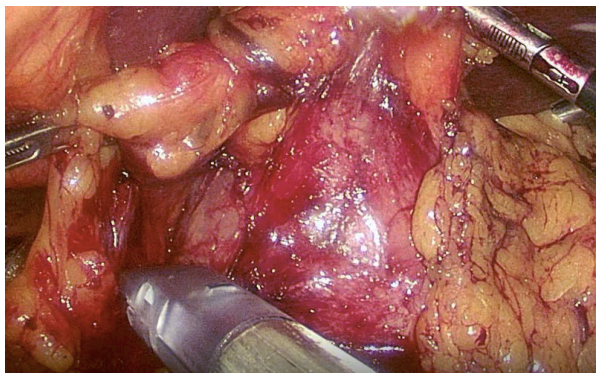

Figure 2. Clipping of right gastro-epiploic vessels.

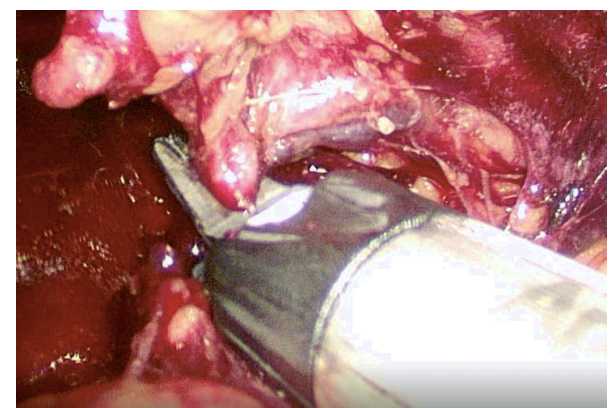

Figure 3. Clipping of left gastric vessels.

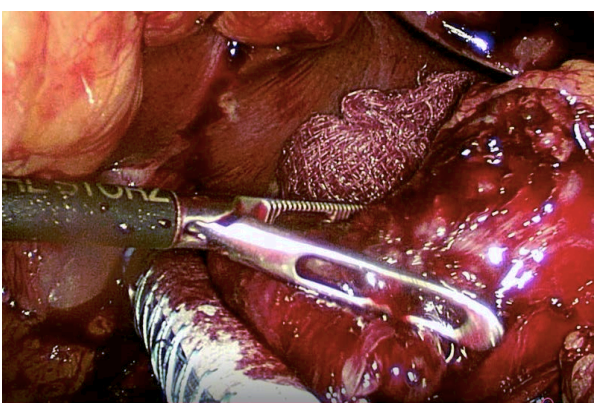

Figure 4. Stapling of the distal end of the stomach.

gastric division was done, at least, $4 \mathrm{~cm}$ proximal to the gross margin of the tumor by repeated firings of the endo-GIA stapler [Figure 5]. The excised specimen was placed in an endo-bag to be retrieved from the umbilical port at the end of the procedure. Reconstruction was performed in the form of a RouxEn-Y gastrojejunostomy using endo-GIA stapler. Two drains were placed in the 


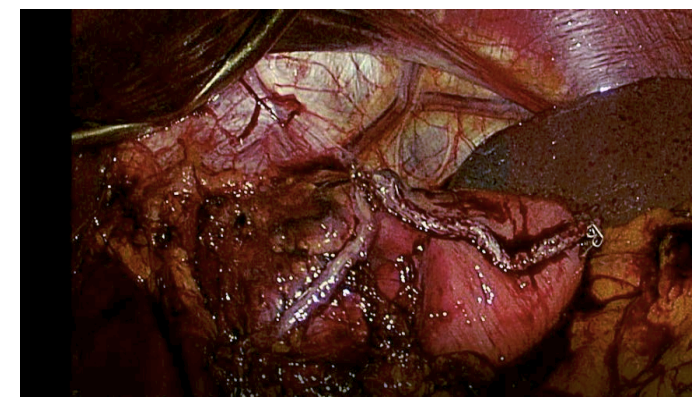

Figure 5. The gastric pouch after complete resection.

hepato-renal space and the lesser sac and the wounds were closed in layers.

In group (A), the abdomen was accessed through a midline incision extending from the Xiphoid process to few centimeters below the umbilicus. The conduct of the procedure is the same as in the laparoscopic approach.

In both groups, the monopolar diathermy, the Harmonic ${ }^{\mathrm{TM}}$ Ultrasonic Shear (Johnson and Johnson Medical, Ethicon, Cincinnati, OH, USA) or the Force$\mathrm{Traid}^{\mathrm{TM}}$ (Vallelab, Covidien, Minneapolis, USA) were used for dissection and haemostasis. The operative time, the intra-operative blood loss and any intraoperative complications were recorded.

\subsection{Postoperative Care}

Post-operatively, patients were put on Ceftriaxone $1 \mathrm{gm} \mathrm{IV/24} \mathrm{hours} \mathrm{and} \mathrm{Me-}$ tronidazole $500 \mathrm{mg}$ IV/8 hours for 24 hours. Postoperative analgesia was provided in the form of Paracetamol $1 \mathrm{gm} \mathrm{IV/6}$ hours and Morphine $5 \mathrm{mg} \mathrm{SC} / 6$ hours on-demand according to the severity of pain. After return of normal gastrointestinal motility, the nasogastric tube was removed and the patients were allowed oral intake with clear fluids increased gradually to full diet over the next few days. The abdominal drain was removed when patients tolerated clear oral fluids provided there was no leak. Patients were discharged home when they were self-dependent, with no or mild pain, tolerated oral intake with no surgical complications.

Postoperative pain severity was assessed using the Visual Analogue Scale (VAS) at 24 hours, 3 and 7 days after the surgery. Postoperative data collected included the severity of postoperative pain as assessed by the VAS, the number of narcotic analgesic injections needed on demand, the time of return of postoperative bowel motility, the postoperative complications, and the length of postoperative hospital stay.

\subsection{Statistical Analysis}

Data were tabulated and analyzed using SPSS Statistics software package version 20. Metric and ordinal data were presented as range and median while nominal data were expressed as percentage. Mann-Whitney test was used to compare metric data while two sample $t$-test was used to compare ordinal data. $P$ value of less than 0.05 was considered statistically significant. 


\section{Results}

\subsection{Demographic}

This study included two matched groups of patients; Group A included 15 patients submitted to open distal gastrectomy and D2 LN dissection and Group B included 12 patients submitted to LDG and D2 LN dissection. The age of the patients in group A ranged from 41 to 67 years with a median of 54 years and male: female ratio of 9:6. In group B, the age ranged from 47 to 60 years with a median of 54.3 years and male: female ratio of 7:5. Associated co-morbidities and the ASA class of patients in the 2 groups were shown in Table 1.

\subsection{Operative Data}

The operative time in group A ranged from 100 to 143 minutes with a median of 118.7 minutes. The intra-operative blood loss ranged from 120 to $180 \mathrm{ml}$ with a median of $152.2 \mathrm{ml}$. The length of the safety margin ranged from 5.6 to 7.8 with a median of $6.52 \mathrm{~cm}$ from the proximal edge of gross tumor. The number of dissected LNs ranged from 18 to 33 with a median of 24.2 LNs. No operative complications were recorded. In group B, the operative time ranged from 185 to 255 minutes with a median of 210.2 minutes. The intra-operative blood loss ranged from 66 to $95 \mathrm{ml}$ with a median of $78.3 \mathrm{ml}$. The length of the safety margin ranged from 5.2 to $7.1 \mathrm{~cm}$ with a median of $5.7 \mathrm{~cm}$. The number of dissected LNs ranged between 17 and 31 with a median of 21.4 LNs. No conversion to laparotomy was needed. One patient developed intraoperative bleeding from the right gastric artery during lesser sac dissection. It was successfully controlled by vascular clips. The differences between the 2 groups in the median operative time and the median intra-operative blood loss were statistically significant

Table 1. Pre-operative patients, data.

\begin{tabular}{|c|c|c|c|c|c|}
\hline \multirow{2}{*}{ Variable } & \multicolumn{2}{|c|}{ Group A $($ No. $=15)$} & \multicolumn{2}{|c|}{ Group B $($ No. $=12)$} & \multirow{2}{*}{$P$ value } \\
\hline & No & $\%$ & No & $\%$ & \\
\hline \multicolumn{6}{|l|}{ Age (years) } \\
\hline - Range & \multicolumn{2}{|c|}{$41-67$} & \multicolumn{2}{|c|}{$47-60$} & \\
\hline - Median & \multicolumn{2}{|c|}{54} & \multicolumn{2}{|c|}{54.3} & 0.904 \\
\hline \multicolumn{6}{|l|}{ Sex } \\
\hline - Male & 9 & 60 & 7 & 58.3 & 0.089 \\
\hline - Female & 6 & 40 & 5 & 41.6 & 0.084 \\
\hline Co-Morbidities & 10 & 66.6 & 6 & 50 & 0.872 \\
\hline - Diabetes Mellitus & 3 & 20 & 2 & 16.6 & \\
\hline - Hypertension & 4 & 26.6 & 3 & 25 & \\
\hline - Arrhythmia & 1 & 6.6 & 0 & 0 & \\
\hline - Coronary Artery Disease & 2 & 13.3 & 1 & 8.3 & \\
\hline \multicolumn{6}{|l|}{ ASA Score } \\
\hline - I & 3 & 20 & 3 & 25 & 0.311 \\
\hline - II & 8 & 53.3 & 6 & 50 & 0.171 \\
\hline - III & 4 & 26.6 & 3 & 25 & 0.094 \\
\hline
\end{tabular}


(118.7 vs 210.2 minutes; $\mathrm{P}<0.01$ and 152.2 vs $78.3 \mathrm{ml}$; $<<0.01$ respectively). On the other hand, the differences between the two groups in the median number of intraoperative complication, tumor grade, $\mathrm{pT}$ stage, tumor size, median length of the least safety margin and median number of dissected LNs were statistically insignificant (Table 2, Table 3).

\subsection{Post-Operative Outcomes}

Post-operatively, the number of narcotic doses ranged from 5 - 11 doses with a median of 5.9 doses in group A while in group B, the number of narcotic doses ranged from $4-6$ doses with a median of 4.25 doses. The median VAS scale at 1 , 3 , and 7 days was $6.6,4.7$, and 2.9 for group A, and 5, 3.8, and 2.2 for group B respectively. The time to pass first flatus ranged from $2-4$ days with a median of 2.7 days in group A while in group B, it ranged from 1 - 3 days with a median of 2.1 days. The length of hospital stay ranged from 6 - 10 days with a median of 7.2 days in group A while it ranged from 6 - 13 days with a median of 7.3 days in group B. The differences between the 2 groups in the median number of analgesic injections, median VAS at 3 and 7 postoperative days were statistically significant. ( $\mathrm{P}=0.04,0.04$, and 0.035 respectively). On the other hand, the difference between the two groups in the median length of hospital stay was found statistically insignificant (7.2 vs 7.3 days; $\mathrm{P}=0.86$ ) (Table 4 ).

Post-operative complications in group A included 2 patients (13.3\%) with wound infection and 1 patient (6.7\%) with pneumonia. In group B, 1 patient (8.3\%) developed pancreatitis in the third post-operative day that was treated conservatively and the patient was discharged on eighth post-operative day. Another patient (8.3\%) developed post-operative leakage on day 6 from the site of gastro-jejunostomy as proven by the CT scan. Since this patient had low output leakage with no intra-abdominal collections, he was treated conservatively by ICU admission, total parenteral nutrition and supportive care. The fistula closed spontaneously with no need for further surgical intervention. The difference between the two groups in the median number of postoperative complications was statistically insignificant ( $3 / 15$ vs $2 / 12 ; \mathrm{P}=0.77)$ (Table 5$)$.

\subsection{Follow up Results}

All the patients were followed in the Surgical Outpatient Clinic 2 weeks postoperatively and they were referred to Oncology Department to receive their adjuvant therapy.

Three months, 6 months, 1 year, \& 2 years follow up to all patients was done, and showed local recurrence in one patient (1 year post-operatively) and lung metastasis in another patient ( 6 months post-operatively). Both patients were in group $\mathrm{B}$ and were treated by palliative chemo-irradiation.

\section{Discussion}

In this study, we report the short term outcomes and our early experience in 
Table 2. Operative findings.

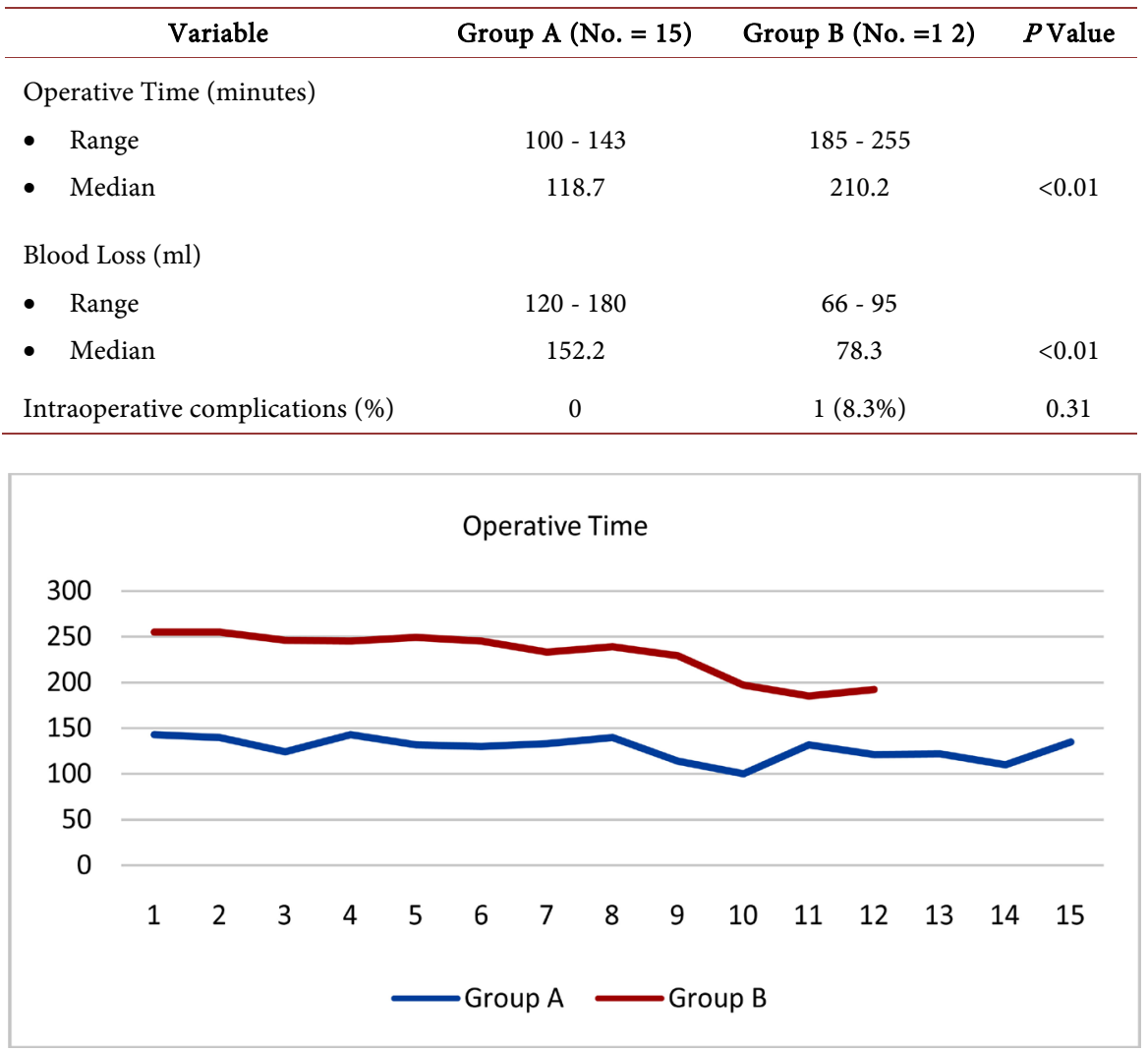

Table 3. Histopathological findings.

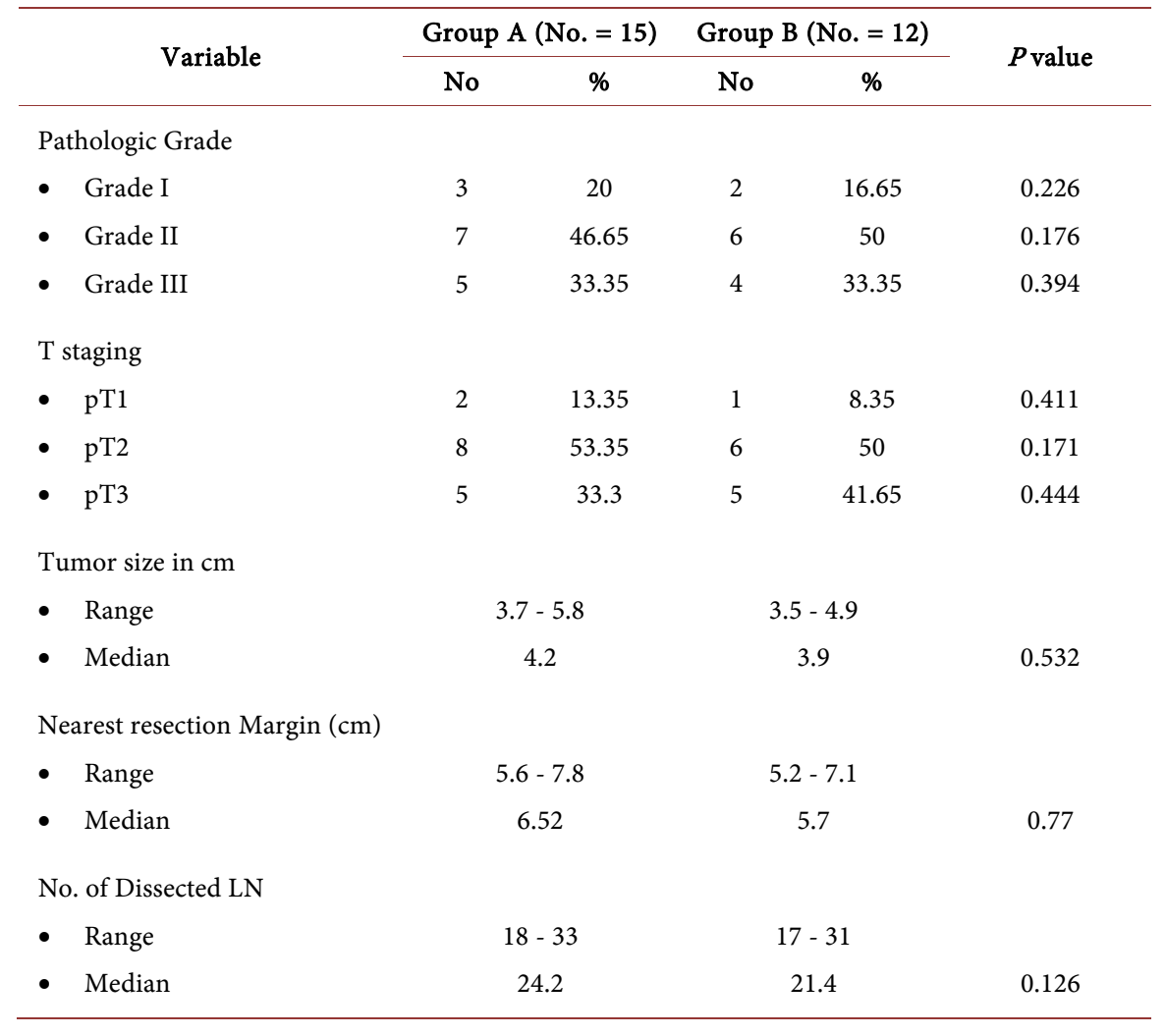


Table 4. Post-operative findings.

\begin{tabular}{lccc}
\hline \multicolumn{1}{c}{ Variable } & Group A $\left(\mathrm{N}_{0}=15\right)$ & Group B $(\mathrm{N}=12)$ & $P$ Value \\
\hline $\begin{array}{l}\text { Number of Narcotic Doses } \\
\text { - Range }\end{array}$ & $5-11$ & $4-6$ & \\
- Median & 5.9 & 4.25 & 0.04 \\
Median VAS Scale & & & \\
- $\quad$ day & 6.6 & 5 & 0.081 \\
- $\quad 3$ days & 4.7 & 3.8 & 0.04 \\
- 7 days & 2.9 & 2.2 & 0.035 \\
Time to Pass First Flatus (days) & & & \\
- Range & $2-4$ & $1-3$ & \\
- Median & 2.7 & 2.1 & 0.15 \\
Length of Hospital Stay (days) & & & \\
- Range & $6-10$ & $6-13$ & \\
- Median & 7.2 & 7.3 & 0.86 \\
\hline
\end{tabular}

Table 5. Post-operative complications.

\begin{tabular}{lccc}
\hline \multicolumn{1}{c}{ Variable } & $\begin{array}{c}\text { Group A (N =15) } \\
\text { No (\%) }\end{array}$ & $\begin{array}{c}\text { Group B (N = 12) } \\
\text { No (\%) }\end{array}$ & $P$ Value \\
\hline Number of Post-Operative Complications: & $3(20)$ & $2(16.6)$ & \\
- Pancreatitis & 0 & 1 & \\
- Wound Infection & 2 & 0 & 0.77 \\
- Pneumonia & 1 & 0 & \\
- Leakage & 0 & 1 & \\
\hline
\end{tabular}

LDG for GA and compare these results with the standard open technique. The study population included two matched groups of patients with no statistically significant differences between the 2 groups in terms of age, sex, comorbid conditions, ASA class and tumor stage (Table 1).

In all patients included in this study, we performed staging laparoscopy before proceeding to definitive surgical resection because we think that staging laparoscopy is a crucial step for detection of occult metastases undetectable on preoperative work-up, thus, avoiding patients with these metastases in the open group unnecessary laparotomies [10] [11].

We excluded patients with previous upper abdominal surgeries because the underlying adhesions may increase the difficulty of the laparoscopy, affect the safety of laparoscopic dissection, and may increase the incidence of conversion to open surgery. Patients with tumors in the upper third of the stomach were also excluded as these patients will need more extensive resection in the form of subtotal or total gastrectomy and may need esophageal resection; techniques that need more complex steps during laparoscopy [12] [13]. For the same reason, we excluded patients with T4 tumors that invade the serosa and/or the surrounding structures [14].

We adopted the rules of proper oncological resection of GA that include a 
minimum safety margin of $4 \mathrm{~cm}$ and D2 LN dissection [14]. The LN dissection in GA should include the perigastric LN (D1) and the LN along the named branches of the celiac artery (D2) with excision of at least 15 LN [15] [16]. Several studies including randomized controlled trial, systematic reviews and metaanalyses, both in Asian and western countries, have shown that D2 LN dissection in advanced GA is associated with improved survival, lower rates of recurrence, and lower rates of cancer-related deaths if compared to D1 dissection [17]-[24]. Nowadays, D2 procedure is recommended as the standard procedure by the Japanese, Korean, German, British, Italian, European Society for Medical Oncology (ESMO) and the joint ESMO-ESSO (European Society of Surgical Oncology)-ESTRO (European Society of Radiotherapy and Oncology) guidelines. Moreover, recently National Comprehensive Cancer Network (NCCN) recommends a D1+ or a modified D2 also in the United States [25].

Although laparoscopic surgery provides the patients with many advantages including smaller incisions, less postoperative pain, faster recovery and better cosmesis, the implementation of this technique in the field of gastric cancer surgery is not widely practiced because LG is technically demanding and needs extensive experience both in laparoscopic and oncologic surgery [26] [27]. Thus, till now, it is currently a matter for debate if LG with D2 lymphadenectomy should represent an appropriate treatment for advanced gastric cancer. Challenging technical issues could be represented by large-size tumors or tumors that require multiorgan resection [28] [29].

The main outcome of this study shows that LDG with D2 LN dissection for distal GA is safe and oncologically sound. Moreover, it provides the patients all the advantages of laparoscopic surgery including reduction of the postoperative pain and the duration of postoperative ileus in comparison to the open approach. These results agree with the results of many other studies [3] [30] [31]. Although the length of hospital stay in our study was longer in the open surgery group, the difference did not reach a statistical significance (7.2 vs 7.3 days; $\mathrm{P}=$ 0.86). This difference can be attributed to the prolonged length of stay for the 2 patients in group B who developed postoperative leakage and pancreatitis and to the small number of patients in our study.

In terms of operative findings, our study showed that, when compared with open surgery, laparoscopy produced significant reduction of median intraoperative blood loss ( 152.2 vs $78.3 \mathrm{ml}$; $\mathrm{p}<0.01$ ), although it was associated with a significant increase in the median operative time (118.7 vs 210.2 minutes; $\mathrm{p}<0.01$ ). Nevertheless, both groups did not show significant differences in the median number of the dissected LN or the median safety margin of excision as shown in Table 3. Our results agree with those of many other studies showing longer operative time and less blood loss for the laparoscopic groups [6] [32] [33] with no difference between laparoscopic and open gastrectomy regarding the least margin of excision and the number of dissected LN [27] [34].

In the open surgery group, 3 patients developed postoperative complications 
which included 2 superficial wound infections and 1 pneumonia. In the laparoscopic surgery group, 2 patients developed complications postoperatively which included postoperative pancreatitis in 1 patient and postoperative leakage in the other. The difference between the two groups was statistically insignificant $(P$ value $=0.77)$. While our results are supported by those of several authors [7] [21] [31], Zeng et al. [12] and Vinuela et al. [35] showed significantly fewer postoperative complications in the laparoscopic group when compared to the open group.

\section{Conclusion}

In conclusion, based on the results of this study, LDG with D2 LN dissection performed for GA is safe, oncologically sound with short-term outcomes comparable to those of open surgery. Moreover, it provides the patients all the advantages of minimally invasive surgery. However, a study on a larger number of patients with a longer follow-up is needed for more valid results. Also, we believe that increasing the experience of the operating surgeons will results in better outcomes.

\section{References}

[1] Zhang, Y., Qi, F., Jiang, Y., et al. (2015) Long Term Follow up after Laparoscopic versus Open Distal Gastrectomy for Advanced Gastric Cancer. International Journal of Clinical and Experimental Medicine, 8, 13564-13570.

[2] Lee, J.H., Lim, J.K., Kim, M.G. and Kwon, S.J. (2014) The Influence of Postoperative Surveillance on the Prognosis after Curative Surgery for Gastric Cancer. Hepato-Gastroenterology, 61, 2123-2132.

[3] Japanese Gastric Cancer Association (2011) Japanese Gastric Cancer Treatment Guidelines 2010 (Version 3). Gastric Cancer, 14, 113-123. https://doi.org/10.1007/s10120-011-0042-4

[4] Kitano, S., Iso, Y., Moriyama, M. and Sugimachi, K. (1994) Laparoscopy Assisted Billroth I Gastrectomy. Surgical Laparoscopy, Endoscopy \& Percutaneous Techniques, 4, 146-148.

[5] Fujiwara, M., Kodera, Y., Misawa, K., et al. (2008) Long Term Outcomes of Early Stage Gastric Carcinoma Patients Treated with Laparoscopy Assisted Surgery. Journal of the American College of Surgeons, 206, 138-143. https://doi.org/10.1016/j.jamcollsurg.2007.07.013

[6] Kim, H.H., Hyung, W.J., Cho, G.S., et al. (2010) Morbidity and Mortality of Laparoscopic Gastrectomy for Gastric Cancer: An Interim Report-A Phase III Multicenter, Prospective, Randomized Trial (KLASS Trial). Annals of Surgery, 251, 417-420. https://doi.org/10.1097/SLA.0b013e3181cc8f6b

[7] Kim, H.H., Han, S.U., Kim, M.C., et al. (2014) Long Term Results of Laparoscopic Gastrectomy for Gastric Cancer: A Large Scale Case Control and Case Matched Korean Multicenter Study. Journal of Clinical Oncology, 32, 627-633. https://doi.org/10.1200//CO.2013.48.8551

[8] Japenese Society for Endoscopic Surgery (2009) Ninth Nationwide Survey of Endoscopic Surgery in Japan. The Japanese Society of Gastroenterological Surgery, 13, 525-529. 
[9] Yoo, C.H., Kim, H.O., Hwang, S.I., et al. (2009) Short Term Outcomes of Laparoscopic Assisted Distal Gastrectomy for Gastric Cancer during a Surgeon's Learning Curve Period. Surgical Endoscopy, 23, 2250-2257. https://doi.org/10.1007/s00464-008-0315-0

[10] Lehnert, T., Rudek, B., Kienle, P., et al. (2002) Impact of Diagnostic Laparoscopy on the Management of Gastric Cancer: Prospective Study of 120 Consecutive Patients with Primary Gastric Adenocarcinoma. British Journal of Surgery, 89, 471-475. https://doi.org/10.1046/j.0007-1323.2002.02067.x

[11] Karanicolas, P.J., Elkin, E.B., Jacks, L.M., et al. (2011) Staging Laparoscopy in the Management of Gastric Cancer: A Population-Based Analysis. Journal of the American College of Surgeons, 213, 644-651. https://doi.org/10.1016/j.jamcollsurg.2011.07.018

[12] Russell, M.C., Hsu, C. and Mansfield, P.F. (2012) Primary Gastric Malignancies. In: Feig, B.W. and Ching, C.D., Eds., MD Anderson Surgical Oncology Handbook, 5th Edition, Lippincott Williams and Wilkins, New York, 270-315.

[13] Quadri, H.S., Hong, Y.K. and Al-Refaie, W.B. (2016) Approach to the Surgical Management of resectable Gastric Cancer. Clinical Advances in Hematology \& Oncology, 14, 249-257.

[14] Ajani, J.A., D’Amico, T.A., Almhanna, K., et al. (2016) Gastric Cancer (Version 3), NCCN Clinical Practice Guidelines in Oncology. National Comprehensive Cancer Network, 14, 1286-1312.

[15] Cunningham, D., Allum, W.H., Stenning, S.P., et al. (2006) Perioperative Chemotherapy versus Surgery Alone for Resectable Gastro-Esophageal Adenocarcinoma. New England Journal of Medicine, 355, 11-20. https://doi.org/10.1056/NEJMoa055531

[16] Ychou, M., Boige, V., Pignon, J.P., et al. (2011) Perioperative Chemotherapy Compared with Surgery Alone for Resectable Gastro-Esophageal Adenocarcinoma: An FNCLCC and FFCD Multicenter Phase III Trial. Journal of Clinical Oncology, 29, 1715-1721. https://doi.org/10.1200/JCO.2010.33.0597

[17] Hartgrink, H.H., van de Velde, C.J., Putter, H., et al. (2004) Extended Lymph Node Dissection for Gastric Cancer: Who May Benefit? Final Results of the Randomized Dutch Gastric Cancer Group Trial. Journal of Clinical Oncology, 22, 2069-2077. https://doi.org/10.1200/JCO.2004.08.026

[18] Songun, I., Putter, H., Kranenbarg, E.M., et al. (2010) Surgical Treatment of Gastric Cancer: 15-Year Follow Up Results of the Randomized Nationwide Dutch D1D2 Trial. The Lancet Oncology, 11, 439-449. https://doi.org/10.1016/S1470-2045(10)70070-X

[19] Degiuli, M., Sasako, M., Ponti, A., Vendrame, A., Tomatis, M., Mazza, C., Borasi, A., Capussotti, L., Fronda, G. and Morino, M. (2014) Randomized Clinical Trial Comparing Survival after D1 or D2 Gastrectomy for Gastric Cancer. British Journal of Surgery, 101, 23-31. https://doi.org/10.1002/bjs.9345

[20] Jiang, L., Yang, K.H., Chen, Y., Guan, Q.L., Zhao, P., Tian, J.H. and Wang, Q. (2014) Systematic Review and Meta-Analysis of the Effectiveness and Safety of Extended Lymphadenectomy in Patients with Resectable Gastric Cancer. British Jour nal of Surgery, 101, 595-604. https://doi.org/10.1002/bjs.9497

[21] Bonenkamp, J.J., Songun, I., Hermans, J., Sasako, M., Welvaart, K., Plukker, J.T., van Elk, P., Obertop, H., Gouma, D.J. and Taat, C.W. (1995) Randomised Comparison of Morbidity after D1 and D2 Dissection for Gastric Cancer in 996 Dutch Patients. Lancet, 345, 745-748. https://doi.org/10.1016/S0140-6736(95)90637-1 
[22] Seevaratnam, R., Bocicariu, A., Cardoso, R., Mahar, A., Kiss, A., Helyer, L., Law, C. and Coburn, N. (2012) A Meta-Analysis of D1 versus D2 Lymph Node Dissection. Gastric Cancer, 15, S60-S69. https://doi.org/10.1007/s10120-011-0110-9

[23] Degiuli, M., Sasako, M. and Ponti, A. (2010) Morbidity and Mortality in the Italian Gastric Cancer Study Group Randomized Clinical Trial of D1 versus D2 Resection for Gastric Cancer. British Journal of Surgery, 97, 643-649. https://doi.org/10.1002/bjs.6936

[24] Biffi, R., Chiappa, A., Luca, F., Pozzi, S., Lo Faso, F., Cenciarelli, S. and Andreoni, B. (2006) Extended Lymph Node Dissection without Routine Spleno-Pancreatectomy for Treatment of Gastric Cancer: Low Morbidity and Mortality Rates in a Single Center Series of 250 Patients. Journal of Surgical Oncology, 93, 394-400. https://doi.org/10.1002/jso.20495

[25] Degiuli, M., De Manzoni, G., Di Leo, A., D’Ugo, D., Galasso, E., Marrelli, D., Petrioli, R., Polom, K., Roviello, F., Santullo, F. and Morino, M. (2016) Gastric Cancer: Current Status of Lymph Node Dissection. World Journal of Gastroenterology, 22, 2875-2893. https://doi.org/10.3748/wjg.v22.i10.2875

[26] Zeng, Y.K., Yang, Z.L., Peng, J.S., et al. (2012) Laparoscopy Assisted versus Open Distal Gastrectomy for Early Gastric Cancer: Evidence from Randomized and Non-Randomized Clinical Trials. Annals of Surgery, 56, 39-52. https://doi.org/10.1097/SLA.0b013e3182583e2e

[27] Ziyu, L., Shan, F., Wang, Y., et al. (2016) Laparoscopic versus Open Distal Gastrectomy for Locally Advanced Gastric Cancer after Neoadjuvant Chemotherapy: Safety and Short Term Oncologic Results. Surgical Endoscopy, 30, 4265-4271.

https://doi.org/10.1007/s00464-015-4739-Z

[28] Goh, P.M., Khan, A.Z., So, J.B., Lomanto, D., Cheah, W.K., Muthiah, R. and Gandhi, A. (2001) Early Experience with Laparoscopic Radical Gastrectomy or Advanced Gastric Cancer. Surgical Laparoscopy, Endoscopy \& Percutaneous Techniques, 11, 83-87. https://doi.org/10.1097/00129689-200104000-00003

[29] Ziqiang, W., Feng, Q,. Zhimin, C., Miao, W., Lian, Q., Huaxing, L. and Peiwu, Y. (2006) Comparison of Laparoscopically Assisted and Open Radical Distal Gastrectomy with Extended Lymphadenectomy for Gastric Cancer Management. Surgical Endoscopy, 20, 1738-1743. https://doi.org/10.1007/s00464-006-0031-6

[30] Kitano, S., Shiraishi, N., Uyama, I., et al. (2007) Japanese Laparoscopic Surgery Study Group: A Multicenter Study on Oncologic Outcome of Laparoscopc Gastrectomy for Early Gastric Cancer in Japan. Annals of Surgery, 245, 68-72. https://doi.org/10.1097/01.sla.0000225364.03133.f8

[31] Hu, Y., Huang, C., Sun, Y., et al. (2016) Morbidity and Mortality of Laparoscopic versus Open D2 Distal Gastrectomy for Advanced Gastric Cancer: A Randomized Controlled Trial. Journal of Clinical Oncology, 34, 1350-1359. https://doi.org/10.1200/JCO.2015.63.7215

[32] Hayashi, H., Ochiai, T., Shimada, H. and Gunji, Y. (2005) Prospective Randomized Study of Open versus Laparoscopy Assisted Distal Gastrectomy with Extra-Perigastric Lymph Node Dissection for Early Gastric Cancer. Surgical Endoscopy, 19, 1172-1176. https://doi.org/10.1007/s00464-004-8207-4

[33] Kim, Y.W., Baik, Y.H., Yun, Y.H., et al. (2008) Improved Quality of Life Outcomes after Laparoscopy Assisted Distal Gastrectomy for Early Gastric Cancer: Results of a Prospective Randomized Clinical Trial. Annals of Surgery, 248, 721-727. https://doi.org/10.1097/SLA.0b013e318185e62e 
[34] Qiu, J., Pankaj, P., Jiang, H., et al. (2013) Laparoscopy versus Open Distal Gastrectomy for Advanced Gastric Cancer: A Systematic Review and Meta-Analysis. Surgical Laparoscopy, Endoscopy \& Percutaneous Techniques, 23, 1-7. https://doi.org/10.1097/SLE.0b013e3182747af7

[35] Vinuela, E.F., Gonen, M., Brennan, M.F., et al. (2012) Laparoscopic versus Open Distal Gastrectomy for Gastric Cancer: A Meta-Analysis of Randomized Controlled Trials and High Quality Non-Randomized Studies. Annals of Surgery, 255, 446-456. https://doi.org/10.1097/SLA.0b013e31824682f4

Submit or recommend next manuscript to SCIRP and we will provide best service for you:

Accepting pre-submission inquiries through Email, Facebook, LinkedIn, Twitter, etc. A wide selection of journals (inclusive of 9 subjects, more than 200 journals)

Providing 24-hour high-quality service

User-friendly online submission system

Fair and swift peer-review system

Efficient typesetting and proofreading procedure

Display of the result of downloads and visits, as well as the number of cited articles Maximum dissemination of your research work

Submit your manuscript at: http://papersubmission.scirp.org/

Or contact ss@scirp.org 